\title{
A INFLUÊNCIA DO CONSTITUCIONALISMO ANDINO CONTEMPORÂNEO NA FORMAÇÃO DE UM PARADIGMA ACERCA DA AGROECOLOGIA
}

\author{
Antônio Carlos Wolkmer \\ Doutor em Direito pela Universidade Federal de Santa Catarina (UFSC). \\ Mestre em Ciência Política pela Universidade Federal do Rio Grande do Sul (UFRGS). \\ Professor do Programa de Pós-Graduação em Direito da UNILASALLE Canoas. \\ Professor Programa de Pós-Graduação em Direito \\ da Universidade do Extremo Sul Catarinense (UNESC). \\ E-mail: acwolkmer@gmail.com \\ Marina Demaria Venâncio

\begin{tabular}{r|} 
Mestranda em Direito pela Pós-Graduação em \\
Direito da Universidade Federal de Santa Catarina (UFSC). \\
Bacharel em Direito pela Universidade Federal de Santa Catarina (UFSC). \\
E-mail: marinademariavenancio@gmail.com
\end{tabular}

\section{RESUMO}

No contexto do Antropoceno, problemas cada vez mais complexos atingem a sociedade em crise. O triplo fardo da má nutrição e a insegurança alimentar são apenas alguns dos exemplos de problemáticas que demonstram a falência do modelo de produção associado à agricultura industrial. Nessa esfera, este artigo objetiva delinear a influência e as contribuições do "novo" constitucionalismo latino-americano, que estabeleceu no continente uma nova visão constitucional pautada no bem viver, no pluralismo jurídico e no direito à segurança alimentar e nutricional (SAN), para o estabelecimento do paradigma agroecológico. Nesse sentido, por intermédio de investigação metodológica documental e indutiva, considerando os avanços presentes nas constituições da Venezuela, do Equador e da Bolívia, a pesquisa busca destacar um conjunto de diretrizes para impulsionar e auxiliar os debates acadêmicos no âmbito das políticas de segurança e de soberania alimentar na América Latina. Tais constituições consistem em relevantes objetos de pesquisa jurídica, visto que fornecem diretrizes epistêmicas e metodológicas para o (re)pensar do papel do direito na transição para a sustentabilidade, apresentando bases para uma verdadeira quebra de 
paradigmas no mundo jurídico, na transição de um direito do agronegócio para um direito da Agroecologia.

Palavras-chave: Antropoceno; "Novo" Constitucionalismo LatinoAmericano; Segurança Alimentar e Nutricional; Soberania Alimentar; Agroecologia.

\author{
THE INFLUENCE OF ANDEAN CONSTITUTIONALISM ON THE \\ FORMATION OF A NEW AGROECOLOGICAL PARADIGM FOR LAW
}

\title{
ABSTRACT
}

In the Anthropocene, increasingly complex problems affect modern societies. The triple burden of malnutrition and food insecurity are some examples of problems that illustrate the failure of modern agriculture and its associated production model. In this sense, this article seeks to outline the influence and some contributions of the Andean Constitutionalism to the formation and consolidation of an agroecological paradigm. The "New" Latin American Constitutionalism has established in the continent a new constitutional perspective, based on the "buen vivir", the legal pluralism and the human right to food. Therefore, this research, by adopting the inductive method and documentary research techniques, analyses the Venezuelan, Ecuadorian and Bolivian constitutions, highlighting a set of guidelines to foster and support the academic debates regarding food safety and sovereignty policies in Latin American. Those constitutions are certainly relevant to legal research, as they provide epistemological and methodological tools and insights to (re)think the role of law in the transition towards sustainability, offering a basis for a paradigm shift in the legal world, to assist the transition from an agribusiness law to an agroecological law.

Keywords: Anthropocene; "New" Latin American Constitutionalism; Food Nutrition and Safety; Food Sovereignty; Agroecology. 


\section{INTRODUÇÃO}

O presente artigo busca identificar algumas contribuições do "novo" constitucionalismo latino-americano - que logrou estabelecer uma nova visão constitucional pautada no bem viver, no pluralismo jurídico e na valorização dos direitos sociais, entre os quais se insere o direito à segurança alimentar e nutricional (SAN) -, realizando uma análise, por meio de investigação metodológica indutiva, que considera os avanços presentes nas constituições da Venezuela, do Equador e da Bolívia, e destacando um conjunto de diretrizes para auxiliar os debates jurídicos no âmbito das políticas de segurança e soberania alimentar. Busca também, discutir o papel e função do Direito na promoção de modelos de desenvolvimento rural mais sustentável.

Certamente, a questão do fornecimento de alimentos suficientes, nutritivos, inócuos e culturalmente adequados a uma população em constante crescimento emerge como um dos grandes desafios para uma nova era geológica (Antropoceno). Situando a discussão no âmbito da América Latina, tem-se que são vários os desafios a serem superados na consecução de uma SAN sustentável no continente, entre os quais se destacam o colapso da agricultura moderna ${ }^{1}$ e a sua resposta ineficaz aos problemas socioambientais complexos.

Tendo em vista esta proposta, dividiu-se a investigação em três momentos. Primeiramente, procura-se contextualizar a problemática na perspectiva do Antropoceno, da sociedade de riscos e da insegurança alimentar, focando-se no continente latino-americano. Em um segundo momento, realiza-se um breve panorama acerca do constitucionalismo andino contemporâneo e suas principais diretrizes, a fim de fornecer um prisma sobre os textos constitucionais da Venezuela, do Equador e da Bolívia. Na sequência, pontuam-se os mais relevantes dispositivos constitucionais desses países no âmbito da SAN, para que seja possível, ao final, realizar uma análise desses instrumentos, delineando-se, em uma perspectiva pluralista, as suas contribuições para os debates no âmbito da segurança e da soberania alimentar.

\footnotetext{
1 Para fins desse estudo, utiliza-se como sinônimas as expressões agricultura moderna, convencional, industrial e capitalista, para identificar o modelo agrícola ainda hegemônico nos países ocidentais, não pautado em princípios de base ecológica, adotado sobretudo após a Revolução Verde, e caracterizado por práticas intensivas; pela dependência de insumos externos; pela a ampla utilização de químicos e produtos da biotecnologia - tais como variedades transgênicas de sementes; e pelo foco na exportação e no lucro.
} 


\section{A DISCUSSÃO SOBRE A SOBERANIA ALIMENTAR E NUTRICIONAL EM UMA NOVA ERA GEOLÓGICA}

Deve-se ter presente que as mudanças climáticas, a fome e a insegurança alimentar são apenas algumas das problemáticas vivenciadas em um momento do desenvolvimento das sociedades modernas em que o homem interveio de tal modo no meio ambiente que as consequências de suas ações se tornaram imprevisíveis, de difícil controle, e abalaram divisão entre o mundo dito natural e o humano. Como bem coloca Purdy (2015), a mais radical expressão desse momento reside na constatação de que a divisão entre esses dois mundos não é mais precisa ou útil, uma vez que a humanidade interfere em tudo o que se encontra a sua volta, moldando dos pontos mais altos da atmosfera às profundezas dos oceanos. Não há mais natureza que se encontre de si dissociada e lugar ou coisa que não tenha sido por si modificada.

O termo Antropoceno, cunhado em 1970 por Stoermer e adotado por um número crescente de cientistas, é assim utilizado para indicar uma nova era geológica na qual a humanidade constitui a força determinante que molda o planeta Terra. Essa interferência antropogênica é tão impactante que, de acordo com estudo recentemente publicado na Revista Nature, ela será responsável por fazer o início da próxima era glacial impossível em quaisquer dos cenários de emissões de gases de efeitos estufa previstos pelo Painel Intergovernamental sobre Mudanças Climáticas (IPCC, sigla em inglês) (GANOPOLSKI, WINKELMANN, SCHELLNHUBER, 2016).

Observa-se, assim, que as crises do Antropoceno têm seu ponto de partida no reconhecimento de que o sistema que se imaginava estável e autossuficiente na resolução de seus problemas é, na realidade, instável e propenso ao colapso (PURDY, 2015). Entre as mais variadas leituras acerca desse momento, o sociólogo Beck $(2012$, p. 8) compreende-o como sendo um estágio da sociedade moderna que não meramente abandona os modos de vida tradicionais, mas também luta contra os efeitos colaterais da modernização de sucesso, com biografias precárias e ameaças incompreensíveis, que afetam a todos e contra as quais ninguém pode adequadamente se prevenir, denominando-o sociedade de risco.

Nessa sociedade, os mecanismos de controle já não conseguem responder aos riscos transfronteiriços, incalculáveis, não compensáveis e complexos ${ }^{2}$ que se apresentam, carecendo de novas abordagens mais

2 A complexidade é, primeiramente, um fenômeno quantitativo, “a extrema quantidade de interações e 
adequadas à natureza dos problemas criados pela força transformadora dos homens. Nesse contexto, a humanidade passa a viver em uma comunidade global de ameaças, na qual os problemas tornam-se comuns, e os Estados já não conseguem administrá-los individualmente (BECK, 2012, p. 8). A herança da revolução verde, que trouxe juntamente com a mecanização e a inovação, os pesticidas, os organismos geneticamente modificados (OGMs) e a submissão dos pequenos produtores às grandes corporações, surgem como um bom exemplo da extensão e da complexidade das ameaças que ultrapassam as fronteiras dos países e afetam os países indistintamente.

Reconhecer, pois, que a espécie humana se encontra no Antropoceno é reconhecer que o homem tem responsabilidades e encontra-se no cerne das crises social, política econômica, e - sobretudo - ambiental de seu século, como uma de suas forças causadoras. Ademais, é igualmente reconhecer a necessidade de caminhar na direção de um modelo de desenvolvimento diferenciado pós-capitalista, que estabeleça perspectivas e estratégias plurais capazes de responder efetivamente às múltiplas crises $^{3}$ que atingem a sociedade, por meio do compromisso com a sustentabilidade ${ }^{4}$, com um melhor equilíbrio entre a natureza e o humano e com o bem-estar ético das futuras gerações.

No âmbito da reflexão sobre um modelo de desenvolvimento sustentável pós-capitalista, este ensaio volta suas atenções às interconexões entre o sistema produtivo e a SAN, que é definida pela Organização das Nações Unidas para Agricultura e Alimentação (FAO, sigla em inglês) como a situação em que "todas as pessoas, a todo o tempo, possuem acesso físico e econômico a alimentos bastantes, seguros e nutritivos para satisfazer suas necessidades alimentares diárias e preferências alimentares, para uma vida ativa e saudável"' (WORLD FOOD SUMMIT, 1996). É

de interferências entre um número muito grande de unidades", que desafiam as possibilidades humanas de cálculo, compreendendo também "incertezas, indeterminações, fenômenos aleatórios" (MORIN, 2011, p. 35). Coincide, portanto, "com uma parte de incerteza, seja proveniente dos limites de nosso entendimento, seja inscrita nos fenômenos", na perspectiva de sistemas ricamente organizados (MORIN, 2011, p.35).

3 Morin (2003, p. 94) denomina esse fenômeno de policrise, já que "não se poderia destacar um problema número um, que subordinaria todos os demais", mas sim diversos problemas vitais que, em conjunto, delineiam a problemática enfrentada pela espécie humana.

4 A sustentabilidade é entendida aqui no sentido de sustentabilidade forte, cujas regras ditam que (1) os recursos renováveis não devem ser utilizados para além de sua taxa de reprodução, (2) os recursos não renováveis devem ser gerenciados economicamente e substituídos por renováveis, e (3) a capacidade de absorção de poluentes não deve excedida (WINTER, 2008, p. 31). Essa noção vai para além do conceito de sustentabilidade pautado nos três pilares (sociedade, economia e meio ambiente) do relatório de Brundtland, o qual compreende que tais três componentes são equivalentes, quando, na realidade, a humanidade depende dos recursos naturais para desenvolver suas atividades.

5 Livre tradução de "all people, at all times, have physical and economic access to sufficient, safe 
possível identificar, ao menos, quatro dimensões neste conceito: (1) a disponibilidade de alimentos, em quantidades de qualidade apropriada; (2) o acesso dos indivíduos a recursos adequados para adquirir alimentos apropriados para uma dieta nutricional; (3) a utilização de alimentos por meio de uma dieta adequada, água potável, tratamento sanitário e de saúde, para que se possa atender a todas as necessidades fisiológicas humanas; (4) e a estabilidade no fornecimento, ou seja, o acesso à alimentação adequada a todos os tempos (FAO, 2014, p. 2016).

Observa-se, assim, que o desafio da SAN, no Antropoceno, ultrapassa o mero fornecimento estável de alimentos em quantidades suficientes, o qual constituía o foco primordial da Conferência Mundial de Alimentação realizada em 1974, em Roma, e passa a abarcar a produção e fornecimento de alimentos nutritivos e de qualidade, que permitam aos seres humanos realizar plenamente seus direitos essenciais, sem deixar de manter a integradora e necessária preservação dos recursos naturais.

Ressalta-se que a problemática da alimentação tornou-se tão complexa que atualmente se discute, para muito além da questão da fome, o que se denominou triplo fardo da má-nutrição. Tais fardos referem-se (1) à fome propriamente dita, ou seja, o consumo de nutrientes abaixo do nível mínimo de consumo diário determinado pela FAO; (2) à fome oculta, que concerne à deficiência de micronutrientes como ferro, zinco e vitamina $\mathrm{A}$; (3) e à obesidade, que diz respeito ao consumo excessivo de energia $\mathrm{e}$ dietas não saudáveis (TOWNSEND, 2016, p.5-26).

Alguns números que auxiliam a ilustrar a extensão desse triplo fardo são aqueles trazidos pelo Fundo das Nações Unidas para a Infância (UNICEF, sigla em inglês) (2013, p.8-15) em relatório que mapeia a nutrição de crianças no mundo. Esse relatório aponta que, no ano de 2011, cerca de 101 milhões de crianças abaixo dos cinco anos no mundo (16\% do total) encontravam-se desnutridas ${ }^{6} ; 165$ milhões de crianças abaixo de cinco anos no mundo ( $26 \%$ do total) apresentavam déficit no índice de altura/idade, comprometendo seu crescimento em longo prazo - taxa conhecida como stunting ${ }^{7}$ em inglês; e 43 milhões de crianças com menos de cinco ( $7 \%$ do total) estavam acima do peso.

and nutritious food to meet their dietary needs and food preferences for an active and healthy life", (WORLD FOOD SUMMIT, 1996).

6 Desnutrição (undernourishment) pode ser definida como "um estado com duração de, pelo menos, um ano, de incapacidade de adquirir comida suficiente, definido como um nível de ingestão de alimentos insuficiente para atender às necessidades energéticas das dietas alimentares" (FAO, 2014, p. 50).

7 Optou-se por utilizar o termo em inglês stunting neste trabalho, em vista da ausência de um correspondente adequado na Língua Portuguesa. 
Tem-se que uma série de fatores vem contribuindo para a intensificação desses problemas ao longo dos últimos anos, entre os quais o sistema alimentar ${ }^{8}$ (TOWNSEND, 2016, p. 5) e as práticas insustentáveis nele praticadas e que necessitam de atenção especial. Nesse sentido, destaca-se a urgência de que os sistemas alimentares deixem de ser parte do problema para tornar-se parte da solução (TOWNSEND, 2016, p. 5), o que perpassa necessariamente pela revisão dos sistemas e técnicas hegemonicamente utilizadas para a produção de alimentos.

Trazendo a discussão para o âmbito da América Latina e do Caribe, observa-se que, apesar do relevante progresso observado no alcance das metas estabelecidas pelos Objetivos de Desenvolvimento do Milênio $(\mathrm{ODMs})^{9}$, os bens ambientais da região encontram-se sob crescente ameaça (PNUMA, 2016, p. 13). Como muito bem coloca o Programa das Nações Unidas para o Meio Ambiente (PNUMA) (2016, p. 13), a falha em lidar com questões fundamentais, tais como a perda de relevantes ecossistemas e espécies, a deterioração de recursos naturais e da água e o aumento das emissões de gases de efeito estufa, irá minar a base sobre a qual muitas das atividades da região dependem, aumentando a vulnerabilidade não só das sociedades latino-americanas, mas também daquelas que compõem o chamado Sul global (África e Ásia), o que muito, provavelmente, impactará profundamente o crescimento econômico e social no futuro.

No âmbito da SAN, destaca-se que, apesar de a região ser uma das maiores produtoras de alimentos do mundo, mais de 37 milhões de pessoas ainda não têm acesso adequado à alimentação (PNUMA, 2016, p. 127). Nesse sentido, aproximadamente $5,5 \%$ das pessoas latino-americanas e caribenhas sofrem de desnutrição (FAO, 2014, p. 8). Igualmente, 12 a $13 \%$ das crianças abaixo dos cinco anos de idade apresentam um déficit no índice de altura/idade, que vem comprometendo seu crescimento em longo prazo (STAHL, 2014, p. 24). Esses dados são ainda mais alarmantes em áreas remotas, com altas concentrações de povos indígenas, que registram uma alta prevalência de stunting quando comparadas ao resto da região (STAHL, 2014, p. 24). Esse é o caso da Guatemala, onde a condição de desnutrição afeta aproximadamente metade das crianças abaixo dos cinco

8 Compreendido como "o conjunto de instituições, recursos, stakeholders e comportamentos envolvidos na produção, transformação, entrega, venda e consumo de alimentos” (TOWNSEND, 2016, p. 5). 9 Os ODS podem ser assim elencados: (1) erradicação da extrema pobreza e da fome, (2) educação universal primária para todos; (3) promoção da igualdade de gênero e empoderamento das mulheres; (4) redução da mortalidade infantil; (5) melhoria da saúde das gestantes; (6) combate ao HIV/AIDS, malária e outras doenças; (7) assegurar a sustentabilidade ambiental; e (8) estabelecimento de uma parceria global para o desenvolvimento (ONU, 2016). 
anos (STAHL, 2014, p. 24-25).

Diante desse cenário, registra-se que a grande demanda na região para, concomitantemente, alimentar a população e atingir as demandas para a exportação de gêneros alimentícios levou à instalação de um modelo agrícola pautado em sistemas intensivos (PNUMA, 2016, p. 128), característicos da agricultura moderna. A alta produtividade desses sistemas reside no amplo uso de terra, herbicidas, pesticidas, fertilizantes químicos, combustíveis e água, além de constantes investimentos em variedades de sementes e maquinários (PNUMA, 2011, p. 40). Tal modelo, além de pressionar os limites biofísicos dos ecossistemas e de produzir alimentos com propriedades nutricionais duvidosas, abala as estruturas sociais dos agricultores familiares e povos tradicionais, contribuindo para a acentuação das desigualdades sociais no campo e para a insegurança alimentar $^{10}$. É possível afirmar, assim, que a agricultura convencional é verdadeiramente insustentável, uma vez que degrada os meios que lhe possibilitariam produzir alimentos em quantidade para suprir a demanda (GLIESSMAN, 2002, p.3).

Nesse contexto, e na perspectiva de um horizonte pluralista, torna-se necessária a popularização, a consolidação e o fortalecimento de estratégias e práticas de desenvolvimento rural na América Latina que se distanciem daquelas largamente empregadas pela agricultura moderna, ou seja, que se demonstrem mais sustentáveis e adaptadas à realidade local, levando em consideração as variadas formas de agricultura sustentável ${ }^{11}$, o papel fundamental dos pequenos agricultores e a valorização dos conhecimentos tradicionais e das sementes crioulas. Tem-se que as propostas de políticas e programas voltados ao campo, nessa região, necessitam incorporar tais aspectos a fim de que possam, de fato, aliviar o triplo fardo, progredir na direção da consecução da SAN e garantir a soberania alimentar.

A soberania alimentar, por sua vez, pode ser definida como "o direito de cada nação ou região de manter e desenvolver sua capacidade de produzir colheitas de alimentos básicos com a diversidade de cultivos correspondente" (ALTIERI, 2010, p. 24). Esse conceito remete fundamentalmente "ao direito dos povos de definir sua política agrária e alimentar, garantindo o abastecimento de suas populações, a preservação do

10 A insegurança alimentar pode ser definida como "a situação que existe quando os indivíduos não têm acesso seguro a quantidades suficientes de alimentos, nutritivos e seguros para um crescimento normal, um desenvolvimento e uma vida ativa e sadia" (FAO, 2014, p. 50).

11 Formas que serão mais bem debatidas na última seção deste trabalho. 
meio ambiente e a proteção de sua produção frente à concorrência desleal de outros países" (MEIRELLES, 2004, p. 11), sendo de extrema relevância para reforçar a autonomia dos povos latino-americanos em definir suas próprias políticas. SAN e soberania alimentar são, pois, conceitos distintos que se comunicam, tendo o segundo uma abrangência mais ampla por tratar dos processos decisórios e da autonomia dos países.

No que concerne mais especificamente à esfera jurídica, situandoa nessa problemática, avalia-se que esses movimentos de popularização, consolidação e fortalecimento de práticas e estratégias rurais devem perpassar a discussão e a abertura de caminhos político-jurídicos para uma revolução no sistema produtivo. Nesse contexto, o Direito, que pareceu por muito tempo perpetuar o sistema dominante, tem um papel importante na quebra de paradigmas.

O mundo jurídico estatista e monocultural (de tradição eurocêntrica) necessita, assim, ultrapassar sua mera função simbólica de manutenção formalista do status quo das políticas agrárias e promover, de forma descentralizadora, participativa e pluralista, mudanças que permitam efetivamente o fortalecimento dos pequenos agricultores e dos povos tradicionais na América Latina. Nesse sentido, o constitucionalismo andino na América latina, representado, mais especificamente, pelas constituições da Venezuela (1999), do Equador (2008) e da Bolívia (2009), apesar dos conhecidos desafios relacionados à implementação de seus textos $^{12}$, trazem-nos interessantes lições no âmbito da SAN e da soberania alimentar, que nos permitem identificar diretrizes inovadoras que podem servir de reflexão a outros sistemas jurídicos, e uma base para uma abertura do Direito na direção complexa e plural de modelos de desenvolvimento mais sustentáveis, conscientes e condizentes aos desafios alimentares que devem ser superados no Antropoceno.

\section{A INSURGÊNCIA DE UM "NOVO" CONSTITUCIONALISMO NA AMÉRICA LATINA}

Antes de aprofundar-se na análise específica dos textos constitucionais dos países objeto deste ensaio, torna-se importante contextualizar a questão no âmbito do constitucionalismo contemporâneo latino-americano, destacando-se, sobretudo, seus aspectos relacionados à

12 Como é o caso da grande oposição conservadora na Bolívia. 
cosmovisão andina e ao meio ambiente ${ }^{13}$.

Registra-se, dessa forma, que a proposta de um "novo" constitucionalismo vem ganhando força ao longo das últimas décadas, em países latino-americanos, sobretudo na Venezuela ${ }^{14}$, no Equador e na Bolívia, países cujo processo político foi profundamente marcado pela insurgência de novos movimentos coletivos que se contrapunham ao neoliberalismo dominante (BAILONE, 2011, p. 151) e às históricas desigualdades sociais na região. Essa proposta rompe com a hegemônica "tradição política e jurídica de base liberal e individualista", distanciandose da matriz eurocêntrica que, por muito tempo, orientou as teorias do Direito e do Estado (WOLKMER, 2014, p. 72).

Coaduna-se, assim, com a noção de uma epistemologia do Sul, que se define como

[...] a chamada por novos processos de produção e de valorização de conhecimentos válidos, científicos e não-científicos, e de novas relações entre diversos tipos de conhecimentos, a partir das práticas das classes e grupos sociais que sofreram de maneira sistemática as injustas desigualdades e as discriminações causadas pelo capitalismo e pelo colonialismo ${ }^{15}$ (SANTOS, 2010, p.43, tradução nossa).

Nesse contexto, o Sul global consiste em uma metáfora do sofrimento humano em escala global e da resistência para superá-lo ou minimizá-lo, não se tratando de um conceito geográfico, apesar da maior parte dos povos afetados habitar os países localizados no hemisfério Sul (SANTOS, 2010, p. 43). É, pois, um "Sul anticapitalista, anticolonial e antiimperialista"16 (SANTOS, 2010, p. 43, tradução nossa), que se emancipa em um processo de (re)valorização e produção de conhecimentos que

13 Isso se justifica em vista da intrínseca relação do meio ambiente com as dimensões de SAN e a busca pela sustentabilidade, visto que só é possível (re)pensar a política e a legislação agrária dentro de um conceito de sustentabilidade forte, que reconheça a finitude dos recursos naturais e a necessidade de respeito aos limites biofísicos do planeta.

14 Cumpre destacar aqui que, em termos de meio ambiente, a sua proteção e manutenção são enquadradas pela constituição venezuelana como um direito-dever de cada geração, que devem fazê-los para o presente e o futuro (VENEZUELA, 1999, art. 127). Ademais, toda pessoa tem o direito, individual e coletivo, de "desfrutar de uma vida e de um ambiente seguro, sadio e ecologicamente equilibrado", sendo uma obrigação fundamental de o Estado garantir que os solos, o clima, a água, inter alia, sejam especialmente protegidos (VENEZUELA, 1999, art. 127).

15 Livre-tradução de: "el reclamo de nuevos procesos de producción y de valoración de conocimientos válidos, cientificos y no cientificos, y de nuevas relaciones entre diferentes tipos de conocimiento, a partir de las prácticas de las clases y grupos sociales que han sufrido de manera sistemática las injustas desigualdades y las discriminaciones causadas por el capitalismo y por el colonialismo" (SANTOS, 2010, p. 43).

16 Livre-tradução de: "Sur anticapitalista, anticolonial y antiimperialista" (SANTOS, 2010, p. 43). 
levem em conta sua identidade e cultura.

Observa-se assim que, partindo-se de um contexto de crise do estado neoliberal (FERNÁNDEZ, 2010, p. 159), a vontade constituinte das classes populares nesses países da América Latina configurou um constitucionalismo "desde baixo", definido por uma ampla mobilização social protagonizada pelos excluídos visando à expansão do campo político para além do liberalismo, por intermédio de "uma institucionalidade nova (plurinacionalidade ${ }^{17}$ ), [...] uma legalidade nova (pluralismo jurídico ${ }^{18}$ ), um regime político novo (democracia intercultural) e novas subjetividades individuais e coletivas (indivíduos, comunidades, nações, povos, nacionalidades)" (SANTOS, 2010, p. 70).

Nesse âmbito, projetaram-se textos constitucionais portadores "de uma cosmovisão alternativa, derivada da valorização do mundo indígena e da refundação das instituições políticas, que reconhecem as necessidades históricas de culturas originárias encobertas de identidades radicalmente negadas ante sua própria história" (WOLKMER, 2014, p. 72). Essas novas constituições definiram o Estado com a fórmula do Estado Social ${ }^{19}$, estabelecendo um regime econômico que, simultaneamente, reconheceu a economia de mercado e garantiu uma ampla intervenção e regulação do Estado na Economia (FERNÁNDEZ, 2010, p. 169). Manifestaram, assim, "uma vontade política de alcançar maiores níveis de justiça social e redistribuição da riqueza, isto é, uma maior realização dos direitos sociais" ${ }^{20}$, os quais se tornaram totalmente protegidos e arguíveis em juízo, com a mesma hierarquia que os direitos políticos e civis (FERNÁNDEZ, 2010, p. 174, tradução nossa).

Um aspecto desse constitucionalismo pluralista andino que é de

$17 \mathrm{Na}$ linguagem dos direitos humanos, a "plurinacionalidade implica o reconhecimento de direitos coletivos dos grupos sociais em situações em que os direitos individuais das pessoas que os integram resultam ineficazes para garantir o reconhecimento e a persistência de sua identidade cultural ou o fim da discriminação social da qual são vítimas" (SANTOS, 2010, p. 81). O reconhecimento da plurinacionalidade implica, portanto, a noção de autodeterminação e autogoverno e demanda o reconhecimento de outro conceito de nação, pautado na pertinência comum a uma etnia, cultura ou religião (SANTOS, 2010, p. 81).

18 Tendo como referência o texto da constituição boliviana, Wolkmer $(2015$, p. 245$)$ pontua que o pluralismo é estabelecido como fundamento do Estado "consagrando o reconhecimento ancestral de formas comunitárias e autônomas de justiça, em que as decisões são tomadas coletivamente para a resolução dos conflitos, buscando vivir bien em equilíbrio entre todos com a natureza".

19 “Estado Democrático y Social de Derecho y de Justicia” (art. 2) na Venezuela (1999), "Estado constitucional de derechos y justicia, social, democrático, soberano, idependiente, unitario, intercultural, plurinacional y laico" (art. 1) no Equador (2008) e "Estado Unitario Social de Derecho Plurinacional Comunitario" (art. 1) na Bolívia (2009).

20 Livre-tradução de: "una voluntad política de potenciar mayores niveles de justicia social y redistribución de la riqueza, esto es, mayores niveles de aseguramiento de los derechos sociales a todos los ciudadanos (FERNÁNDEZ, 2010, p. 174). 
grande relevância para esta investigação é o reconhecimento, sobretudo pelas constituições equatoriana e boliviana, do direito ao desenvolvimento do bem viver, denominado também de suma qamaña (Bolívia) ou sumak kawasay (Equador).

O sumak kawsay ${ }^{21}$ consiste em uma expressão quéchua que significa pleno-viver ou bem viver, "[...] cujo conteúdo não é outra coisa que a ética - não a moral individual - que deve reger a ação do Estado e conforme a qual as pessoas também devem relacionar-se entre si e, em especial, com a natureza" (ZAFFARONI, 2001, p. 111).

Destaca-se que a constituição equatoriana operou um verdadeiro giro biocêntrico, reconhecendo não somente o sumak kawasay como também direitos próprios da natureza (WOLKMER, 2015, p. 244). Dessa forma, seu preâmbulo reforça a decisão do povo de construir "uma nova forma de convivência cidadã, em diversidade e harmonia com a natureza, para alcançar o bem viver; [e] uma nova sociedade que respeita, em todas suas dimensões, a dignidade das pessoas e das coletividades" 22 (EQUADOR, 2008). Seguindo a mesma linha, o art. 71 dispõe que a natureza - ou Mãe Terra - detém o direito de respeito à sua existência e à manutenção e regeneração de suas funções, estruturas e ciclos vitais (EQUADOR, 2008).

A Constituição do Equador declara, assim, o direito de todos de viver em um ambiente sadio e ecologicamente equilibrado, que garanta a sustentabilidade e o bem viver (art.14), determinando como de interesse público "a preservação do ambiente, a conservação dos ecossistemas, a biodiversidade, a integridade do patrimônio genético do país, a prevenção do dano ambiental e a recuperação dos espaços naturais degradados" ${ }^{23}$ (EQUADOR, 2008, art. 14, tradução nossa). Observa-se, desde já, que a lógica mercadológica e depredatória da agricultura moderna, de manutenção de grandes latifúndios manejados intensivamente, não encontra muito espaço nesse novo modelo constitucional.

Como muito bem elucida Zaffaroni (2011, p. 111), a Mãe Terra (Madre Tierra) assume a condição de um verdadeiro sujeito de direitos, incorporando todos os seres vivos, não reduzido ou limitado aos humanos.

21 Conhecido na Bolívia como suma qamaña.

22 Livre-tradução de: "Una nueva forma de convivencia ciudadana, en diversidad y armonía con la naturaleza, para alcanzar el buen vivir; Una sociedad que respeta, en todas sus dimensiones, la dignidad de las personas y las colectividades [...]" (EQUADOR, 2008).

23 Livre-tradução de: "la preservación del ambiente, la conservación de los ecosistemas, la biodiversidad y la integridad del patrimonio genético del país, la prevención del daño ambiental y la recuperación de los espacios naturales degradados" (EQUADOR, 2008, art. 14). 
Dessa forma, tais direitos podem ser reclamados por qualquer vivente, humano e não humano, em amplo espectro de abrangência. Tal consagração trata-se de um corolário alcançado pelos movimentos sociais e pelas lutas campesinas (BAILONE, 2011, p. 157) e sua invocação implica uma obrigação de respeito ao meio ambiente e a todas as formas de vida, que se traduz na regra ética fundamental do bem viver (ZAFFARONI, 2011, p.111).

Em sentido parecido, a constituição boliviana, que representa o marco fundamental da institucionalização do pluralismo jurídico (WOLKMER, 2015, p. 244), faz remissão à Mãe Terra em seu preâmbulo, que inclui, entre os princípios ético-morais da sociedade plural, a vida boa (tekokavi), a vida harmoniosa (ñandereko) e o viver bem (suma qamaña) (art. 8) (BOLÍVIA, 2009). Ademais, o texto constitucional determina o direito de todos a "um meio ambiente saudável, protegido e equilibrado", devendo o exercício desse direito "permitir os indivíduos e coletividades das presentes e futuras gerações, além dos outros seres vivos, desenvolverse de maneira normal e permanente" ${ }^{24}$ (art. 33) (BOLÍVIA, 2009, tradução nossa).

Diante desse breve panorama acerca do constitucionalismo pluralista andino, estabelece-se, dessa forma, um prisma que facilita a compreensão e a contextualização dos princípios, mecanismos e diretrizes estabelecidas pelos textos constitucionais da Venezuela, do Equador e da Bolívia no âmbito da segurança e da soberania alimentar na América Latina. Esses textos constitucionais conceberam uma ótica diferenciada para a questão, que se coaduna com uma abertura, na esfera do Direito e no horizonte do continente, na direção de um modelo de desenvolvimento rural mais sustentável, conforme se observará na sequência deste estudo.

\section{A SOBERANIA ALIMENTAR E A AGRICULTURA SUSTENTÁ- VEL NO CONSTITUCIONALISMO CONTEMPORÂNEO LATI- NO-AMERICANO}

No contexto do triplo fardo da má-nutrição que atinge a América Latina, bem como das crises do Antropoceno e de sistemas jurídicos que precisam repensar-se e oferecer respostas a uma sociedade de riscos,

24 Livre-tradução de: "Las personas tienen derecho a un medio ambiente saludable, protegido y equilibrado. El ejercicio de este derecho debe permitir a los individuos y colectividades de las presentes y futuras generaciones, además de otros seres vivos, desarrollarse de manera normal y permanente" (BOLÍVIA, 2009, art. 33). 
que já não encontra mais as soluções para seus problemas dentro de seus mecanismos de controles tradicionais, as novas constituições latinoamericanas destacam-se como um interessante objeto de estudo, exatamente por inovar na tradicional maneira de pensar as funções dos atores rurais e os métodos produtivos.

As três constituições são, assim, trabalhadas nessa seção em ordem cronológica, apontando-se seus mais relevantes dispositivos, identificados em pesquisa predominantemente documental, nos eixos relacionados à SAN (disponibilidade, acesso, utilização e estabilidade no fornecimento de alimentos), que servem de base para a discussão no âmbito da temática realizada na seção seguinte.

\subsection{O caso da Venezuela}

A Constituição da República Bolivariana da Venezuela de 1999 elencou as políticas nacionais e a legislação em matéria de segurança alimentar como competências do poder público nacional ${ }^{25}$ (VENEZUELA, 1999). Importantes medidas relacionadas à segurança alimentar estão consagradas no artigo 305 do Título VI (Sistema Socioeconômico), que estabelece a produção de alimentos como de interesse nacional, tratando-a como elemento fundamental para o desenvolvimento econômico e social da Nação (VENEZUELA, 1999).

O dispositivo supramencionado constitucionaliza o conceito de segurança alimentar, que é definida como "a disponibilidade suficiente e estável de alimentos no âmbito nacional e o acesso oportuno e permanente a estes por parte do público consumidor"26 (VENEZUELA, 1999). Igualmente, define a agricultura sustentável como a base estratégica do desenvolvimento rural para alcançá-la, o que deve ocorrer por intermédio do desenvolvimento e privilégio da produção agropecuária interna, ou seja, aquela proveniente das atividades agrícola, pecuária, pesqueira e aquícola (VENEZUELA, 1999).

Ressalta-se que o artigo 305 da Constituição de Venezuela define as competências do Estado de: (1) editar as medidas (financeiras, comerciais, de transferência tecnológica, i.a.) necessárias para atingir

$25 \mathrm{Na}$ Venezuela o poder público se divide entre Poder Municipal, Poder Estatal e Poder Nacional. Este último, ao qual se refere o texto, é aquele que se divide entre Legislativo, Executivo, Cidadã e Eleitoral (VENEZUELA, 1999).

26 Livre-tradução de "o la disponibilidad suficiente y estable de alimentos en el ámbito nacional y el acceso oportuno y permanente a éstos por parte del público consumidor” (VENEZUELA, 1999, art. $305)$. 
níveis estratégicos de auto abastecimento; (2) promover ações na esfera da economia nacional e internacional para compensar as desvantagens inerentes à atividade agrícola; e (3) proteger os assentamentos e comunidades de pescadores artesanais, bem como seus locais de pescas em águas continentais e em regiões próximas a linha de costa (VENEZUELA, 1999).

Nesse mesmo sentido, o art. 306 prevê, com o intuito de gerar empregos, de garantir um nível adequado de bem-estar à população campesina e de promover a sua incorporação ao desenvolvimento nacional, o dever do Estado de promoção das condições (e.g. crédito) para o desenvolvimento rural integral, fomentando a atividade agrícola e o uso otimizado da terra (VENEZUELA, 1999).

Já o art. 307 determina o regime latifundiário como contrário ao interesse social, sendo responsabilidade do Estado zelar pela ordenação sustentável das terras agrícolas e assegurar seu potencial agroalimentar (VEZUELA, 1999). Esse artigo também reconhece o direito dos campesinos e demais produtores à propriedade da terra, nos termos e casos da lei específica (VENEZUELA, 1999).

Destaca-se que outro dispositivo de extrema relevância para os debates no âmbito da segurança alimentar é o artigo 124, inserido no Capítulo VIII dos povos indígenas ${ }^{27}$, que garante a propriedade intelectual coletiva dos seus conhecimentos, inovações e tecnologias (VENEZUELA, 1999). Nesse sentido, todas as atividades associadas a esses povos e relacionadas com recursos genéticos e conhecimentos tradicionais devem perseguir benefícios coletivos, proibindo-se, assim, o registro de patentes ${ }^{28}$ sobre os recursos e conhecimentos ancestrais (VENEZUELA, 1999). Tal discussão é extremamente pertinente quando se situa o debate no contexto do patenteamento desses saberes pelas grandes corporações, sobretudo de

\footnotetext{
27 No que tange aos indígenas, cumpre destacar que o texto constitucional reconhece a existência dos povos e comunidades indígenas, sua cultura, organização (social, política e econômica), religiões e direitos originários sobre as terras que ocupam (VENEZUELA, 1999, art. 119). Igualmente, consagra o direito desses povos às suas atividades produtivas tradicionais, à participação na economia nacional, à definição de suas prioridades e à manutenção e promoção de suas próprias práticas econômicas (VENEZUELA, 1999, art. 123).

28 Este dispositivo coaduna-se com a decisão 391 de 1996 da Comunidade Andina (Comissão do Acordo de Cartagena), que criou o Regime Comum Andino de Acesso aos Recursos Genéticos e determinou aos países membros que não reconheçam "direitos, incluídos os de propriedade intelectual, sobre recursos genéticos, produtos derivados ou sintetizados e componentes intangíveis associados, obtidos ou desenvolvidos a partir de uma atividade de acesso que não cumpra com as [suas] disposições" (COMUNIDADE ANDINA, 1996, tradução nossa). A legislação infraconstitucional venezuelana, notadamente a Ley de laDiversidad Biológica de 2000, posteriormente revogada pela Ley de Gestión de La Diversidad Biológica de 2008, seguiram a mesma linha, garantindo a propriedade intelectual coletiva e a proibição do patenteamento.
} 
insumos e de sementes, que dominam grande parte dos mercados latinoamericanos.

\subsection{Equador: seus parâmetros constitucionais}

Já a Constituição da República do Equador inclui, entre os deveres primordiais do Estado, a garantia indiscriminada ao direito à alimentação, que se associa especialmente também aos direitos à saúde, à liberdade (a uma vida digna) e ao meio ambiente sadio (art. $3^{\circ}$ e seguintes) (EQUADOR, 2008). Nessa linha, determina no Capítulo II, dedicado aos direitos do Bem Viver, que as "pessoas e coletividades têm direito ao acesso seguro e permanente a alimentos saudáveis, suficientes e nutritivos; preferencialmente produzidos em nível local e em correspondência com suas diversas identidades e tradições culturais"29 (art. 13) (EQUADOR, 2008, tradução nossa), alinhando-se às diversas dimensões que podem ser atribuídas ao conceito de SAN discutidas na primeira seção deste trabalho.

Ademais, o artigo 13 identifica o Estado como competente pela promoção da soberania alimentar (EQUADOR, 2008), ou seja, como incumbido da tarefa de definir suas próprias políticas agrárias e alimentares, buscando, concomitantemente, atender às necessidades regionais, preservar o meio ambiente e administrar sustentavelmente seus recursos. Nessa esfera, o artigo 304 da Constituição do Equador inclui entre os objetivos da política comercial a contribuição para a garantia dessa soberania (EQUADOR, 2008).

É importante destacar aqui que a Constituição do Equador dedica um capítulo inteiro, situado no título IV (Regime de Desenvolvimento), à soberania alimentar ${ }^{30}$, que passa, com o advento da nova legislação, a constituir "um objeto estratégico e uma obrigação do Estado para garantir que as pessoas, comunidades, povos e nacionalidades alcancem a autossuficiência de alimentos saudáveis e culturalmente adequados de maneira permanente"31 (art. 281) (EQUADOR, 2008, tradução nossa).

29 Livre-tradução de: "Las personas y colectividades tienen derecho al acceso seguro y permanente a alimentos sanos, suficientes y nutritivos; preferentemente producidos a nivel local y en correspondencia con sus diversas identidades y tradiciones culturales" (EQUADOR, 2008, art. 13).

30 Cumpre destacar aqui que a matéria foi regulamentada em 2009 pela Ley Orgánica del Régimen de La Sobernaía Alimentaria.

31 Livre-tradução de: "un objetivo estratégico y una obligación del Estado para garantizar que las personas, comunidades, pueblos y nacionalidades alcancen la autosuficiencia de alimentos sanos y culturalmente apropiado de forma permanente" (EQUADOR, 2008, art. 281). 
Neste capítulo, composto por dois artigos, o artigo 281 elenca quatorze itens que contêm responsabilidades do Estado equatoriano no âmbito da soberania alimentar, as quais podem ser assim enumeradas: (1) o estímulo à produção e à transformação agroalimentar e pesqueira das unidades de produção médias e pequenas, das comunidades e da economia social e solidária; (2) a adoção de políticas econômicas (fiscais, tributárias e tarifárias) de proteção do setor de alimentos nacional; (3) a consolidação da diversificação e da introdução de tecnologias orgânicas e ecológicas na produção agropecuária; (4) a promoção de políticas redistributivas no âmbito dos recursos naturais produtivos; (5) o estabelecimento de mecanismos preferenciais de financiamento para produtores de pequeno e médio porte; (6) a promoção da agrobiodiversidade e dos conhecimentos tradicionais a si relacionados, bem como o uso, conservação e intercâmbio livre de sementes; (7) o asseguramento de que os animais destinados ao consumo humano tenham sido criados em um ambiente saudável e estejam sadios; (8) a garantia do desenvolvimento da pesquisa científica e da inovação tecnológica; (9) a regulação do desenvolvimento, experimentação, uso e comercialização das biotecnologias; (10) o fortalecimento do desenvolvimento de organizações e redes de consumidores e produtores, de comercialização e distribuição de gêneros alimentícios; (11) o impedimento de práticas monopólicas e qualquer tipo de especulação, criando sistemas justos e solidários de distribuição e comercialização de alimentos; (12) o fornecimento de alimentos a populações vítimas de desastres naturais e antrópicos ${ }^{32}$; (13) a prevenção e proteção da população contra o consumo de alimentos contaminados que apresentem riscos à sua saúde; e (14) a compra de materiais e alimentos prioritariamente de redes associativas de pequenos produtores para programas sociais e alimentícios (EQUADOR, 2008). Nota-se, em especial, a preocupação do constituinte com a economia local e o abastecimento interno, bem como o enfoque dado aos pequenos e médios produtore ${ }^{33}$ como elementos essenciais do sistema agroalimentar.

Ressalta-se, ademais, que a carta equatoriana, finalizando o capítulo terceiro, dispõe que a terra deve cumprir sua função socioambiental, proibindo-se a concentração de terras e o latifúndio (art. 282) (EQUADOR,

32 Não podendo os alimentos recebidos de ajudas internacionais afetar a saúde e o futuro da produção de alimentos locais (EQUADOR, 2008, art. 281).

33 Nesse sentido, o artigo 373 da Constituição do Equador prevê um regime especial do seguro universal obrigatório, denominado seguro social campesino, para proteger a população rural e as pessoas dedicadas a pesca artesanal (EQUADOR, 2008, art. 373). 
2008). Nesse sentido, cria-se um Fundo Nacional da Terra (FNT) ${ }^{34}$, que deverá regular o acesso equitativo de campesinos à terra (art. 282) (EQUADOR, 2008).

Além disso, o texto proíbe, em seu artigo 15, a consecução da soberania energética ${ }^{35}$ em detrimento da alimentar (EQUADOR, 2008). Entende-se que tal dispositivo auxilia, por exemplo, a tomada de decisões no âmbito da produção de alimentos para fabricação de biocombustíveis de primeira geração, os quais são elaborados a partir de matérias vegetais produzidos pela agricultura, o que se torna apenas aceitável - em virtude do texto - nas situações em que a soberania alimentar do país não esteja ameaçada.

No que concerne ao polêmico tópico dos OGMs, o artigo 15 veda o desenvolvimento, a produção, a posse, a comercialização, a importação, o armazenamento e o uso de contaminantes orgânicos persistentes altamente tóxicos, de tecnologias e agentes biológicos experimentalmente nocivos, de agroquímicos internacionalmente proibidos e de OGMs prejudiciais para a saúde humana ou que atentem contra os ecossistemas ou a soberania alimentar (EQUADOR, 2008). Na mesma linha, o artigo 400 declara o Equador um país livre de cultivos e sementes transgênicas, que somente podem ser introduzidas em caso de interesse nacional fundamentado pela Presidência da República e aprovado pela Assembleia Nacional (EQUADOR, 2008). Tal dispositivo inclui e destaca o Equador como um dos poucos países do mundo em que são proibidos tanto o cultivo quanto a importação de transgênicos.

Ainda no que tange aos dispositivos concernentes à SAN, pontuase que cabe ao Estado equatoriano desenvolver políticas de fomento à produção nacional na promoção do acesso equitativo aos fatores de produção (art. 334) e apoiar as comunidades rurais e agricultores na conservação e na restauração dos solos e no desenvolvimento de práticas agrícolas protetivas (art. 410). Igualmente se proíbe, na mesma linha venezuelana, toda forma de apropriação de conhecimentos coletivos (sobretudo patenteamento), no âmbito das ciências, das tecnologias e dos saberes ancestrais, bem como a apropriação de recursos genéticos que contenham a diversidade biológica e a agrobiodiversidade (art. 322) (EQUADOR, 2008).

Por fim, vale a pena ressaltar que o país se comprometerá a

34 O FNT foi efetivamente criado por intermédio da publicação da Ley Orgánica de Terras Rurales y Territorios Ancestrales, em 14 de março de 2016 (EQUADOR, 2016).

35 Nos termos do artigo 413, o Estado deverá promover “[...] energias renováveis, diversificadas, de baixo impacto e que não ponham em risco a soberania alimentar [...]" (EQUADOR, 2008). 
promover estratégias coordenadas de soberania alimentar com os demais países da América latina, sendo a integração regional um objetivo estratégico do país (art. 423) (EQUADOR, 2008).

\subsection{A legislação na Bolívia}

A última das constituições a ser analisada neste trabalho, a Constituição Política do Estado da Bolívia de 2009, traz o direito à alimentação em seu rol de direitos fundamentais, estabelecendo a obrigação do Estado de garantir a segurança alimentar por intermédio de uma alimentação sadia, adequada e suficiente para toda a população (art.15) (BOLÍVIA, 2009). Em termos de SAN, o artigo 71 dispõe que os consumidores e usuários têm direito ao fornecimento - oportuno e eficiente - de alimentos em condições de inocuidade, qualidade e quantidade adequada e suficiente (BOLÍVIA, 2009).

Destaca-se que as temáticas relacionadas à $\mathrm{SAN}^{36}$ são, em grande parte, trabalhadas no Título III, que é dedicado à regulamentação do desenvolvimento rural integral sustentável, parte fundamental das políticas econômicas do Estado (art. 405) (BOLÍVIA, 2009). Nesse sentido, a administração deve atingi-lo por "intermédio de políticas, planos, programas e projetos integrais de fomento à produção agropecuária, artesanal, florestal e ao turismo"37 (art. 406), levando em conta: (1) o incremento sustentado e sustentável da produtividade agropecuária e agroindustrial; (2) a articulação entre as estruturas de produção agropecuárias e agroindustriais; (3) a busca por melhores condições de intercâmbio econômico do setor produtivo rural com o resto da economia do país; (4) a valorização e o respeito às comunidades indígenas originárias campesinas; (5) o fortalecimento da economia familiar e comunitária, bem como dos pequenos produtores (art. 405) (BOLÍVIA, 2009, tradução nossa). Devem-se priorizar, assim, ações que busquem o desenvolvimento do conjunto dos atores rurais e dos empreendimentos econômicos comunitários (art. 405) (BOLÍVIA, 2009, art. 405), em detrimento de ações voltadas à apenas um setor específico.

O Título III também estabelece como competência do Estado

36 Enaltece-se que o país tem uma rica legislação no âmbito da temática, surgida após a Constituição de 2009, destacando-se a Ley Marco de la Madre Tierra y Desarrollo Integral para Vivir Bien, de 15 de outubro de 2012; a Ley de Organizaciones Enconómicas Campesinas, Indígena Originarias e Organizaciones Económicas Comunitarias, de 26 de janeiro de 2013; e a Ley de Alimentación Escolar em el Marco de la Soberanía Alimentaria y la Economía Plural, de 29 de dezembro de 2014.

37 Livre-tradução de: "por medio de políticas, planes, programas y proyectos integrales de fomento a la producción agropecuaria, artesanal, forestal y al turismo" (BOLÍVIA, 2009, art. 406). 
o fortalecimento e a promoção das organizações econômicas produtivas rurais, tais como as dos artesãos, as cooperativas, as associações e "as micro, pequenas e médias empresas comunitárias agropecuárias, que contribuam para o desenvolvimento econômico social do país, de acordo com sua identidade cultural e produtiva" ${ }^{38}$ (art. 406) (BOLÍVIA, 2009).

Os objetivos da política de desenvolvimento rural integral sustentável são colocados pelo artigo 407, podendo ser assim elencados: (1) garantia da segurança e soberania alimentar, priorizando-se o consumo de alimentos agropecuários produzidos no país; (2) estabelecimento de mecanismos de proteção à produção interna; (3) promoção da produção e comercialização de produtos agroecológicos; (4) proteção das atividades agropecuárias e agroindustriais contra desastres naturais e sinistros; (5) desenvolvimento e implementação de todos os níveis e modalidades de educação técnica produtiva e ecológica; (6) estabelecimento de projetos e políticas de maneira sustentável; (7) promoção de seguros para a produção agropecuária; (8) provimento de assistência técnica e estabelecimento de mecanismos de inovação e de transferência tecnológica ao longo da cadeia produtiva agropecuária; (9) criação de um banco de sementes e centros de investigação genética; (10) prestação de fomento e apoio aos setores produtivos cuja estrutura seja naturalmente debilitada; (11) controle do fluxo dos recursos biológicos e genéticos; (12) estabelecimento de políticas e programas no âmbito da inocuidade alimentar e da sanidade agropecuária; e (13) provimento de infraestrutura e serviços básicos ao setor agropecuário (BOLÍVIA, 2009).

Ainda no âmbito do desenvolvimento rural e finalizando o Título III, o artigo 408 estabelece como dever do Estado a determinação de auxílios em benefício dos pequenos e médios produtores, visando à compensação das desvantagens oriundas do intercâmbio desproporcional entre os produtos agropecuários e o resto da economia (BOLÍVIA, 2009).

Ressalta-se que compete também ao Estado "fomentar planos de assentamentos humanos para alcançar uma distribuição demográfica racional e um melhor aproveitamento da terra e dos recursos naturais, outorgando aos novos assentados facilidades de acesso à educação, à saúde, 'segurança alimentar e à produção"39 (art. 402) (BOLÍVIA, 2009, tradução nossa).

\footnotetext{
38 Livre-tradução de: "las micro, pequeñas y medianas empresas comunitarias agropecuarias, que contribuyan al desarrollo económico social del país, de acuerdo a su identidad cultural y productiva (BOLÍVIA, 2009, art. 406).

39 Livre-tradução de "Fomentar planes de asentamientos humanos para alcanzar una racional distribución demográfica y un mejor aprovechamiento de la tierra y los recursos naturales, otorgando a los nuevos asentados facilidades de acceso a la educación, salud, seguridad alimentaría y producción [...]"
} 
No âmbito da propriedade intelectual, cumpre pontuar que as nações e povos indígenas originários campesinos têm direito à propriedade intelectual coletiva dos saberes, ciências e conhecimentos, bem como a sua valorização, o uso, a promoção e o desenvolvimento (art. 30) (BOLÍVIA, 2009).

Já no tocante à questão da concentração de terras, na mesma linha das constituições venezuelana e equatoriana, a Constituição da Bolívia proíbe o latifúndio e a dupla titularidade de terras, uma vez que os compreende como contrários ao desenvolvimento do país e ao interesse nacional (art. 398) (BOLÍVIA, 2009).

No que concerne à questão energética, destaca-se que, à semelhança do texto constitucional equatoriano, o boliviano pauta-se no incentivo a fontes alternativas e renováveis de energia, desde que respeitada a segurança alimentar da população, como fica claro na redação do artigo 300, 16 (BOLÍVIA, 2009). Nesse sentido, é injustificada a busca da segurança energética em detrimento da alimentar.

$\mathrm{Na}$ esfera internacional, o artigo 255 elenca como princípios norteadores da negociação, subscrição e ratificação de tratados internacionais: (1) o alcance da SAN e da soberania alimentar e (2) a proibição de importação, produção e comercialização de OGMs e de elementos tóxicos que causem danos à saúde e ao meio ambiente (BOLÍVIA, 2009).

Nesse contexto, no que tange aos OGMs, verifica-se que há uma aparente contradição no texto constitucional, visto que o artigo 409 predispõe que lei específica regulará a produção, a importação e a comercialização de alimentos transgênicos (BOLÍVIA, 2009). Dito isso, vale a pena mencionar que a questão da proibição ou não desses gêneros é um debate aceso na Bolívia, cujo futuro ainda é incerto em vista das contradições políticas e legislativas envolvidas na matéria ${ }^{40}$, que não constituem o foco desse trabalho.

No âmbito da legislação infraconstitucional, a título de complementação, cumpre destacar que, em abril de 2010, foi proclamada

(BOLÍVIA, 2009, art. 402).

40 A título de complementação destaca-se que, com exceção da soja transgênica (permitida por decisão governamental), hodiernamente a introdução, a produção, o uso, a liberação ao meio ambiente e comercialização de sementes geneticamente modificadas é, em tese, proibida no território boliviano, consoante a Ley Marco de la Madre Tierra y Desarrollo Integral para Vivir Bien de 2012 (BOLÍVIA, 2012). Todavia, a Ley de Revolución Productiva de 2011 dá margem para o ingresso de transgênicos de cultivos em que a Bolívia não é centro de origem ou diversidade (BOLÍVIA, 2011), sendo o debate pró e contra a liberação muito aceso no cenário político. 
na Bolívia a Declaração Universal dos Direitos da Mãe Terra, que trabalhou com o conceito de Mãe Terra e reconheceu-a como uma "comunidade indivisível vital dos seres interdependentes e inter-relacionados com um destino comum" (CONFERÊNCIA..., 2010). Nesse sentido, consoante essa Declaração, a natureza foi reconhecida pela legislação infraconstitucional como um "sujeito vivente", consolidando normativamente a cosmovisão ancestral (WOLKMER; FERRAZZO, 2015, p. 38). As leis representativas dessa consolidação são a Lei n. 71, de 21 de dezembro de 2010, conhecida como Lei dos Direitos da Mãe Terra, e a Lei n. 300, de 15 de outubro de 2012, intitulada Lei Marco da Mãe Terra e Desenvolvimento Integral para o Bem Viver. Em especial, a Lei n. 300/12 ressalta que o Estado promoverá o direito à alimentação com soberania e segurança alimentar, levando em consideração, complementarmente, todos os objetivos do bem viver (BOLÍVIA, 2012). Providenciam, portanto, um interessante aporte infraconstitucional para as questões debatidas nessa pesquisa.

\section{O FORTALECIMENTO DA SEGURANÇA ALIMENTAR E NUTRICIONAL NA AMÉRICA LATINA}

Observa-se, em uma primeira análise dos dispositivos trazidos pelas constituições andinas, que essas constituições inauguram sistemas constitucionais muito próprios e únicos para lidar com a questão da segurança e da soberania alimentar, concedendo-lhes destaque. São, assim, dotadas de uma ótica que incorpora a visão do Sul, sobretudo dos movimentos sociais camponeses e povos originários e tradicionais, que influenciaram seus processos de conformação. Essa característica torna essas constituições relevantes objetos jurídicos de estudo, mormente em um contexto global do "sistema mundo" no qual se desperta para a complexidade dos problemas causados pelo modelo produtivo adotado desde a revolução verde e para a consequente necessidade de re)valorizar os recursos, os povos, as redes, as culturas e as tradições locais.

No que concerne mais especificamente aos seus dispositivos, a Constituição da Venezuela determina a produção de alimentos como interesse nacional, constitucionalizando o conceito de segurança alimentar e definindo a agricultura sustentável como base estratégia do desenvolvimento rural.

Já as constituições do Equador e da Bolívia assemelham-se em 
diversos pontos, sobretudo em decorrência da consagração do direito ao bem viver, compartilhando cosmovisões afins. Nesse sentido, a primeira inclui a alimentação entre os direitos (fundamentais) do bem viver; constitucionalizando a SAN ao tratar do acesso seguro e permanente a alimentos saudáveis, suficientes e nutritivos, produzidos localmente e adaptados à sua cultura local. Igualmente, dedica um capítulo inteiro à soberania alimentar, fazendo menção direta à promoção da produção e da comercialização de produtos agroecológicos, e declara o Equador como um país livre de OGMs, proibindo, inclusive, sua importação.

A segunda, por sua vez, também declara o direito à alimentação como fundamental, constitucionalizando a obrigação do Estado de garantir a segurança alimentar (alimentação sadia, adequada e suficiente) e estabelecendo uma robusta política de desenvolvimento rural integral sustentável. Destaque-se também que ambas as constituições fornecem a fundação para a conformação de uma rica legislação infraconstitucional para o combate da insegurança alimentar, o que é comprovado pelas inúmeras leis específicas promulgadas no âmbito da matéria ao longo dos últimos anos, tais como a Lei Marco da Mãe Terra e Desenvolvimento Integral para o Bem Viver (2012) - boliviana.

De modo geral, é possível extrair algumas lições dessas constituições em termos de elementos relevantes para a operação de mudanças significativas nos sistemas alimentares, com o intuito de tornálos mais sustentáveis e atuantes na solução dos problemas do Antropoceno, bem como de atender à SAN, ou seja, à produção de alimentos suficientes, de qualidade nutricional e sanitária adequadas, compatíveis com a cultura daqueles que deles se beneficiarão.

Tais lições podem ser organizadas, para fins didáticos, em uma de lista de doze diretrizes, que podem servir de ponto de partida para uma interessante discussão jurídica dos elementos a serem considerados na esfera da SAN. É possível enumerar assim: (1) a valorização da produção local; (2) o incentivo à agricultura sustentável como base para o desenvolvimento rural; (3) o apoio à agricultura familiar ${ }^{41}$; (4) a promoção das pequenas e médias propriedades rurais; (5) a proibição da acumulação de terras e dos latifúndios; (6) a proteção dos conhecimentos tradicionais;

\footnotetext{
41 Destaca-se que a agricultura familiar, fenômeno complexo e multidimensional, define-se não somente pela maneira com a qual os agricultores familiares cultivam e vivem, mas também pelo tamanho dos estabelecimentos (PLOEG, 2014, p. 7). Pode ser assim definida como um "meio de organização das produções agrícola, florestal, pesqueira, pastoril e aquícola, que são gerenciadas e operadas por uma família e predominantemente dependente de mão de obra familiar, tanto de mulheres quanto de homens" (FAO, 2014, p. 2).
} 
(7) a (re)valorização da cultura local; (8) o fortalecimento da economia e das redes locais; (9) o intercâmbio de sementes crioulas; (10) o banimento dos OGMs; (11) o banimento de pesticidas e químicos que apresentem riscos à saúde animal e humana; e (12) o incentivo à pesquisa no âmbito da agricultura sustentável.

Quadro 1 - Diretrizes do constitucionalismo andino latino-americano para um novo paradigma na produção de alimentos

\begin{tabular}{|c|c|}
\hline Diretriz & Exemplos de Correspondência Constitucional \\
\hline (1) Valorização da produção local & Privilégio da agropecuária interna (Equador, art. 305) \\
\hline $\begin{array}{l}\text { (2) Incentivo à agricultura sustentável, } \\
\text { como base para o desenvolvimento } \\
\text { rural }\end{array}$ & $\begin{array}{l}\text { Promoção da agricultura sustentável (Venezuela, art. } \\
\text { 305); introdução de tecnologias ecológicas e orgânicas na } \\
\text { produção agropecuária (Equador, art. 281); promoção da } \\
\text { produção de produtos agroecológicos (Bolívia, art. 126). }\end{array}$ \\
\hline (3) Apoio à agricultura familiar & $\begin{array}{llcl}\text { Compreendida como fenômeno complexo } & \text { e } \\
\text { multidimensional, depreende-se das demais diretrizes }\end{array}$ \\
\hline $\begin{array}{l}\text { (4) Promoção das pequenas e médias } \\
\text { propriedades rurais }\end{array}$ & $\begin{array}{l}\text { Expressa em todas as constituições analisadas, e.g. } \\
\text { incentivo a pequenas e médias unidades de produção } \\
\text { (Bolívia, art. 281) }\end{array}$ \\
\hline $\begin{array}{l}\text { (5) Proibição da acumulação de terras } \\
\text { e dos latifúndios }\end{array}$ & $\begin{array}{l}\text { Expressa em todas as constituições analisadas, e.g. } \\
\text { proibição e definição de latifúndio (Bolívia, 398) }\end{array}$ \\
\hline $\begin{array}{l}\text { (6) Proteção dos conhecimentos } \\
\text { tradicionais }\end{array}$ & $\begin{array}{l}\text { Propriedade intelectual coletiva dos conhecimentos, } \\
\text { tecnologias e inovações dos povos indígenas (Venezuela, } \\
\text { art. 124; Equador, art. 322; Bolívia, art. 30) }\end{array}$ \\
\hline (7) (Re)valorização da cultura local & $\begin{array}{l}\text { Inerente à própria conformação dos Estados pluralistas, } \\
\text { e.g. Estado Plurinacional equatoriano (Equador, art. 1). } \\
\text { Vale ainda destacar a recuperação dos saberes ancestrais } \\
\text { vinculados à agrobiodiversidade (Equador, art. 281) }\end{array}$ \\
\hline $\begin{array}{l}\text { (8) Fortalecimento da economia e das } \\
\text { redes locais }\end{array}$ & $\begin{array}{l}\text { Desenvolvimento de redes de produtores e consumidores } \\
\text { e de comercialização e distribuição de alimentos } \\
\text { (Equador, art. 281), economia plural, cooperativismo } \\
\text { (Bolívia, art. 306) }\end{array}$ \\
\hline (9) Intercâmbio de sementes crioulas & Intercâmbio livre de sementes (Equador, art. 281) \\
\hline (10) Banimento dos OGMs & País livre de OGMs (Equador, art. 401) \\
\hline $\begin{array}{l}\text { (11) Banimento de pesticidas e } \\
\text { químicos que apresentem riscos à } \\
\text { saúde animal e humana }\end{array}$ & $\begin{array}{l}\text { Proteção da população contra alimentos contaminados } \\
\text { (Equador, art. 281), inocuidade dos alimentos (Bolívia, } \\
\text { art. 75) }\end{array}$ \\
\hline $\begin{array}{l}\text { (12) Incentivo à pesquisa no âmbito } \\
\text { da agricultura sustentável }\end{array}$ & $\begin{array}{l}\text { Desenvolvimento de pesquisa para o setor agrícola } \\
\text { (Venezuela, art. 307), garantia da SAN (Equador, art. } \\
\text { 281), saberes ancestrais (Equador, arts. } 386 \text { e 387), } \\
\text { manejo, conservação e aproveitamento dos recursos } \\
\text { naturais (Bolívia, art. 354) }\end{array}$ \\
\hline
\end{tabular}

Fonte: Elaborado pelo Autor. 
Diante dessas diretrizes, observa-se que as constituições analisadas sedimentaram bases jurídicas para uma verdadeira quebra de paradigmas no âmbito do Direito, que rompem com a tradição neoliberal na direção da consolidação de relevantes instrumentos para mudanças no perfil das políticas agrárias e ambientais, estabelecendo um novo parâmetro hermenêutico para análise das normas e um novo perfil para a legislação infraconstitucional em seus respectivos países.

Em síntese, importa registrar a relevância da conexão desses sistemas constitucionais com a Agroecologia, que foi expressamente mencionada pela Constituição boliviana. Essa é uma ciência que estuda a aplicação de conceitos ecológicos para o desenho de agroecossistemas sustentáveis (ALTIERI, 2012, p.104) e que, na América latina, também ficou conhecida como uma teoria crítica, uma prática concreta e um movimento social. Agroecologia é, pois, um conceito que reúne essas diferentes acepções e vai para muito além de uma mera prática de agricultura sustentável. As suas contribuições incorporam "dimensões mais amplas e complexas, que incluem tanto variáveis econômicas, sociais e ambientais, como variáveis culturais, políticas e éticas da sustentabilidade" (CAPORAL; COSTABEBER, 2004, p. 13).

Nesse sentido, entende-se que o constitucionalismo contemporâneo na América Latina também abriu portas, em uma via de mão dupla, para uma maior aceitação e consolidação da Agroecologia como ciência, teoria, prática e movimento social, criando caminhos plurais para uma verdadeira "revolução agroecológica" no âmbito dos sistemas produtivos e, quiçá, dos sistemas políticos e jurídicos.

\section{CONCLUSÃO}

Diante do exposto, torna-se significativo retomar alguns pontoschaves que foram debatidos ao longo deste ensaio. Primeiramente, observou-se que o homem vive em meio a problemas globais e complexos na era do Antropoceno. Isto implicou no reconhecimento de que a espécie humana é também responsável pelas crises de seu tempo e precisa caminhar na direção de um modelo de desenvolvimento diferenciado, de natureza pós-capitalista, sobretudo no que se relaciona aos bens comuns e, mais especificamente, no tocante à segurança e à soberania alimentar.

Nessa esfera, constatou-se que a América Latina, apesar de ter registrado significativos avanços no alcance das metas dos ODMs, 
sofre ainda com o triplo fardo da má-nutrição, sendo o sistema produtivo marcado pela agricultura moderna, um dos grandes responsáveis por vários dos problemas estruturais verificados.

Nesse contexto, o constitucionalismo na experiência andina, por intermédio de uma perspectiva do Sul, traz uma proposta diversificada pautada no pluralismo, na interculturalidade e na cosmovisão indígena, que assegura o direito ao viver bem (bem viver). Sob essa ótica, foram analisadas as constituições da Venezuela, do Equador e da Bolívia, buscando-se identificar pontos que se comunicam com a temática da SAN. Constata-se que esses textos constitucionais abordam o assunto de uma forma singular, inaugurando sistemas constitucionais diversificados e alternativos, que incorporaram a visão dos povos originários e tradicionais e dos movimentos sociais camponeses como sujeitos coletivos que participaram de seu processo de conformação.

Constituem, assim, interessantes objetos de pesquisa jurídica, que não somente fornecem diretrizes epistêmicas e metodológicas para o (re)pensar do papel do Direito na transição para um futuro mais sustentável, como também apresentam as bases para uma quebra de paradigmas no mundo jurídico, ou seja, a transposição de um direito do agronegócio para um direito da Agroecologia.

Em suma, cumpre à presente contribuição impulsionar um debate acadêmico no âmbito da consecução da SAN no continente latinoamericano, proporcionando elementos capazes de sedimentar as bases para uma verdadeira revolução agroecológica na sociedade e no Direito.

\section{REFERÊNCIAS}

ALTIERI, Miguel. Agroecologia: Bases científicas para uma agricultura sustentável.

3. ed. São Paulo: Expressão Popular; AS-PTA, 2012.

BAILONE, Matías. El bienvivir: una cosmovisión de los pueblos originarios andino-amazónicos. In: ZAFFARONI, Eugenio Raul. La pachamama y el humano. Buenos Aires: Ediciones Madres de Plazas de Mayo, 2011, p. 149-158.

BECK, Ulrich.World at risk. Cambridge: Polity Press, 2012. 
BOLÍVIA. Constituição (2009). Constitución Política del Estado. El Alto de La Paz: 2009. Disponível em: <http://www.gacetaoficialdebolivia.gob. bo/index.php/normas/descargar/36208>. Acesso em: 15 set. 2016.

BOLÍVIA. Ley de Derechos de La Madre Tierra, de 21 de dezembro de 2010. Disponível em: <http://www.mineria.gob.bo/juridica/20101206-1742-21.pdf>. Acesso em: 28 mar. 2017.

BOLÍVIA. Ley de Revolución Productiva, de 26 de junho de 2011. Disponível em: <http://www.gacetaoficialdebolivia.gob.bo/index.php/ normas/compendio/Agraria >. Acessoem: 16 set. 2016.

BOLÍVIA. Ley Marco de la Madre Tierra y Desarrollo Integral para Vivir Bien, de 15 de outubro de 2012. Disponível em: <http://www.ine.gob.bo/ indicadoresddhh/archivos/alimentacion/nal/Ley $\% 20 \mathrm{~N} \% \mathrm{C} 2 \% \mathrm{~B} 0 \% 20300$. pdf $>$. Acesso em: 16 set. 2016.

BRASIL. Constituição (1988). Constituição da República Federativa do Brasil de 1988. Brasília, DF: Senado Federal, 1988.

CAPORAL, Francisco Roberto; COSTABEBER, José Antônio. Agroecologia: Alguns conceitos e princípios. Brasília: MDA; SAF; FAERIICA, 2004.

COMUNIDADE ANDINA. Régimen Común sobre Acceso a los Recursos Genéticos.Decisãon.391,de02dejulhode1996.Disponívelem: <http://www. minambiente.gov.co/images/BosquesBiodiversidadyServiciosEcosistemicos/ pdf/Recursos_Gen\%C3\%A9ticos_/Decisi\%C3\%B3n_391_de_1996.pdf >. Acesso em: 15 set. 2016.

CONFERÊNCIA MUNDIAL DOS POVOS SOBRE A MUDANÇA CLIMÁTICA E OS DIREITOS DA MÃE TERRA. Declaração Universal dos Direitos da Mãe Terra. Cochabamba, 2010. Disponível em: <http:// rio20.net/pt-br/propuestas/declaracao-universal-dos-direitos-da-maeterra/>. Acesso em: 20 mar. 2017.

EQUADOR.Constituição(2008). Constitución de la RepúblicadelEcuador. Quito: 2008. Disponível em: <http://www.asambleanacional.gob.ec/sites/ 
default/files/private/asambleanacional/filesasambleanacionalnameuid-20/ transparencia-2015/literal-a/a2/Const-Enmienda-2015.pdf $>$. Acesso em 15 set. 2016.

EQUADOR. Ley Orgánica de Terras Rurales y TerritoriosAncestrales, de 14 de março de 2016. Disponível em: <http://www.asambleanacional.gob. ec/es/leyes-aprobadas $>$. Acesso em: 15 set. 2016.

EQUADOR. Ley Orgánica del Régimen de La Soberanía Alimentaria, de 5 de maio de 2009. Disponível em: $<$ http://www.soberaniaalimentaria.gob. ec/pacha/wp-content/uploads/2011/04/LORSA.pdf >. Acesso em: 15 set. 2016.

[FAO]FOODANDAGRICULTUREORGANIZATION.AnoInternacional da Agricultura Familiar. Roma, 2014. Disponível em: <http://www.fao. org/docrep/019/as281p/as281p.pdf >. Acesso em: 28 ago. 2016.

[FAO] FOOD AND AGRICULTURE ORGANIZATION. Food Security. Policy Brief. Roma: F.A.O., 2006. Disponível em: <ftp://ftp.fao.org/es/ ESA/policybriefs/pb_02.pdf $>$. Acesso em: 28 ago. 2016.

[FAO] FOOD AND AGRICULTURE ORGANIZATION. The state of food insecurity in the world. Roma, 2014. Relatório. Acesso em: $<\mathrm{http}: / / \mathrm{www}$. fao.org/3/a-i4030e.pdf>. Disponível em: 28 ago. 2016.

FERNANDÉZ, Albert Noguera. Los derechos sociales en las nuevas constituciones Latinoamericanas. Valencia: Tirant Lo Blanch, 2010.

GANOPOLSKI, Andrey; WINKELMANN, Ricarda; SCHELLNHUBER, Joachim.critical insolation-CO2 relation for diagnosing past and future glacial inception. Nature, [S.1.], v. 529, jan. 2016.

GLIESSMAN, Stephen. Agroecología: procesos ecológicos en agricultura sostenible. Turrialba, Costa Rica: CATIE, 2002. Versão em espanhol do original em inglês.

MAZOYER, Marcel; ROUDART, Laurence. História das agriculturas no mundo: do neolítico à crise contemporânea. Tradução Cláudia F. Falluh 
Balduino Ferreira. São Paulo: UNESP, 2010.

MEIRELLES, Laércio. Soberania alimentar, agroecologia e mercados locais. Agriculturas, v. 1, p. 11-14, set. 2004.

MIGUEL, Altieri. Agroecologia, agricultura camponesa e soberania alimentar. Revista Núcleo de Estudos, Pesquisas e Projetos de Reforma Agrária, São Paulo, n. 16, p. 22-32, jan./jun. 2010.

MATTEI, Ugo. Bienes Comunes. Un Manifiesto. Madrid: Trotta, 2013.

MORIN, Edgar. Introdução ao pensamento complexo. Porto Alegre: Sulina, 2011.

MORIN, Edgar; KERN, Anne Brigitte. Terra-Pátria. Porto Alegre: Sulina, 2003.

[ONU] ORGANIZAÇÃO DAS NAÇÕES UNIDAS. Millennium development goals and beyond 2015. Disponível em: <http://www.un.org/ millenniumgoals/>. Acesso em: 28 ago. 2016.

ROSA, Enéias da; BURITY, Valéria A.; CONTI, Irio L. (Orgs.). Derecho Humano a la Alimentación en América Latina. Passo Fundo: Berthier, 2004.

TOWNSEND, Robert. et al. Future of food: Shaping the global food system to deliver improved nutrition and health. Washington, 2016. Relatório. Disponível em: <http://documents.worldbank.org/curated/ en/474831468186561685/pdf/104757-WP-Future-of-Food-Nut-HealthWeb-PUBLIC.pdf>. Acesso em: 24 set. 2016.

[UNICEF] FUNDO DAS NAÇÕES UNIDAS PARA A INFÂNCIA. Improving child nutrition: The achievable imperative for global progress. Nova York, 2013. Relatório. Disponível em: <https://www.unicef.org/gambia/ Improving_Child_Nutrition_-_the_achievable_imperative_for_global progress.pdf $>$. Acesso em: 24 set. 2016.

VENEZUELA. Constituição(1999). Constitución de la República Bolivariana 
de Venezuela. Caracas: 1999. Disponível em $<$ http://gobiernoenlinea.gob.ve/ home/archivos/ConstitucionRBV1999.pdf>: Acesso em: 31 jul. 2016.

[PNUMA] PROGRAMA DAS NAÇÕES UNIDAS PARA O MEIO AMBIENTE. Global environment outlook GEO-6 Regional assessment for Latin America and the Caribbean. Nairobi, 2016.Relatório.

[PNUMA] PROGRAMA DAS NAÇÕES UNIDAS PARA O MEIO AMBIENTE. Towards a Green Economy: Pathways to Sustainable Development and

PovertyEradication. GRID-Arendal, 2011. Diponível em: <http://www.grida. no/publications/green-economy/ebook.aspx $>$. Acesso em: 28 ago. 2016.

PLOEG, Jan Douwe van der. Dez qualidades da agricultura familiar. Agriculturas: Experiências em agroecologia, Rio de Janeiro, n. 1, p. 6-14, fev. 2014. Disponível em: <http://aspta.org.br/wpcontent/uploads/2014/02/ Agriculturas_Caderno_Debate-N01_Baixa.pdf $>$.Acesso em: 29 ago. 2014.

PURDY, Jedediah. After nature. 1 ed. Cambridge: Harvard University Press, 2015.

SANTOS, Boaventura de Sousa. Refundación del Estado en América Latina: Perspectivas desde una epistemología del Sur. Lima: Instituto Internacional de Derecho y Sociedad; Programa Democracia y Transformación Social, 2010.

STAHL, Robert. Starving, Stunted... Obese? Berkeley Review of Latin American Studies, Berkeley, p.24-26, mar. 2014.

WINTER, Gerd. A fundament and two pillars: The concept of sustainable development 20 years after the Brundtland report. In: BUGGE, Hans Christian; VOIGT, Christina. Sustainable development in international and national law: What did the Brundtland report do to legal thinking and legal development, and where can we go from here? [S.1.]: Europa Law, 2008.

WOLKMER, Antonio Carlos. Ética da sustentabilidade e direitos da natureza no constitucionalismo latino-americano. In: LEITE, José Rubens Morato; PERALTA, Carlos. Perspectivas e desafios para a proteção da biodiversidade 
no Brasil e na Costa Rica. São Paulo: Planeta Verde, 2014, p. 67-84.

WOLKMER, Antonio Carlos. Pluralismo jurídico: Fundamentos de uma nova cultura do direito. 4. ed. São Paulo: Saraiva, 2015.

WOLKMER, Antonio Carlos; FERRAZZO, Débora. Interculturalidade, Meio Ambiente e Constitucionalismo: Novas Perspectivas Sociais. In: SÁNCHEZ BRAVO, Álvaro; CERVI, Jackson R. (Orgs.). Multiculturalismo, Tecnología y Medio Ambiente. Sevilla: Punto Rojo, 2015. p. 19-45.

WORLD FOOD SUMMIT. World Food Summit Plan of Action.13 nov. 1996. Roma. Disponívelem: $<$ http://www.fao.org/wfs/index_en.htm>. Acesso em: 28 ago. 2016.

ZAFFARONI, Eugenio Raul. La pachamama y el humano. Buenos Aires: Ediciones Madres de Plazas de Mayo, 2011. 158 p.

Artigo recebido em: 05/04/2017. Artigo aceito em: 16/08/2017.

\section{Como citar este artigo $(\mathrm{ABNT})$ :}

WOLKMER, Antônio Carlos; VENÂNCIO, Marian Demaria. A Influência do Constitucionalismo Andino Contemporâneo na Formação de um Paradigma Acerca da Agroecologia. Veredas do Direito, Belo Horizonte, v. 14, n. 29, p. 261-291, mai./ago. 2017. Disponível em: <http://www. domhelder.edu.br/revista/index.php/veredas/article/view/1047>. Acesso em: dia mês. ano. 